\title{
The inhibitory effect of Isoliquiritigenin on the proliferation of human arterial smooth muscle cell
}

\author{
Tianbao Chen ${ }^{1}$, Shaoxiong Deng ${ }^{2}$ and Rong Lin ${ }^{*}$
}

\begin{abstract}
Background: Isoliquiritigenin (ISL) has various biological activities including as antioxidant and an inhibitor of PI3K AKT signaling pathway. However, both oxidative stress and activated PI3K/AKT signaling contribute to the aberrant proliferation of vascular smooth muscle cells (VSMCs). This study is aimed to explore the effect of ISL on the proliferation of human arterial smooth muscle cells (HASMCs) and to investigate the underlying mechanisms.

Methods: BrdU incorporation, cell cycle and reactive oxygen species (ROS) in normal or ISL treated HASMCs were analyzed by flow cytometry. Cell viablity was measured by CCK-8. Protein expression levels were examined by Western blot, and superoxide dismutase (SOD) activity was detected by using commercial kit.

Results: We observed that ISL could inhibit the proliferation of HASMCs in a dose and time dependent manner. Cell cycle of ISL treated HASMCs arrested mainly in G1/S phase and accompanied with elevated expression of p27 and decreased expression of CyclinD1 and CyclinE. In addition, ISL could down-regulated the expression of p-PI3K and p-AKT, alleviated oxidative stress and enhanced the SOD activity in HASMCs. Furthermore, $\mathrm{H}_{2} \mathrm{O}_{2}$ treatment partly improved cell viability and up regulated p-PI3K and p-AKT in HASMCs.

Conclusions: Therefore, we concluded that ISL inhibited the proliferation of HASMCS via attenuating oxidative stress and suppressing PI3K/AKT signaling pathway. The inhibitory effect of ISL on PI3K/AKT signaling pathway, at least partly, was mediated by ROS.
\end{abstract}

Keywords: Isoliquiritigenin, HASMCs, Proliferation, Oxidative stress, PI3K signaling

\section{Background}

The aberrant proliferation of VSMCs is thought to be a key event in plaque formation of atherosclerosis [1]. Both in vitro and in vivo studies indicate that inhibiting VSMCs proliferation could be a strategy for delaying atherosclerosis progression [2-4]. The underlying mechanisms and molecules involved in cell-cycle regulation of VSMCs had been studied a lot. Among which, oxidative stress is generally acknowledged as one of primary contributors. Multiple studies had demonstrated that eliminating of the excessive ROS could decrease the proliferation of VSMCs significantly [5-7].

\footnotetext{
* Correspondence: ronglinedu@163.com

1Department of Cardiology, First Hospital of Quanzhou Affiliated to Fujian Medical University, NO. 205, East Street, Licheng District, Quanzhou, Fujian, China

Full list of author information is available at the end of the article
}

Isoliquiritigenin (ISL) from licorice compounds showed various biological activities including antioxidant and anti-inflammatory properties [8,9]. Previous study has revealed ISL could significantly inhibit cytokineinduced endothelial cell adhesion molecule expression [10]. Further study has demonstrated that the inhibitory effect of ISL on cell adhesion molecule expression, partly depended on its function in blocking ROS generation [11]. Besides antioxidant and anti-inflammatory properties, ISL is regarded as a nature inhibitor of PI3K/AKT signaling pathway in breast cancer [12]. And, PI3K/AKT signaling pathway is also necessary for VSMCs proliferation [13-15]. Taken together, we propose that ISL may effectively suppress the proliferation of VSMCs through inhibiting oxidative stress and molecules in PI3K/AKT signaling. It has been reported that ROS could modulate PI3K/AKT signaling pathway via several manners such 
as deactivating PTEN or protein phosphatase 2A [16-18]. Therefore, we will investigate whether the inhibitory effect of ISL on PI3K/AKT signaling pathway is mediated by ROS.

In present study, we report that: 1) ISL inhibits the proliferation of HASMs in a dose and time dependent manner. 2) Inhibitory effect of ISL on HASMCs proliferation at least partly depends on attenuating oxidative stress and suppressing PI3K/AKT signal pathway. 3) The modulation of PI3K/AKT pathway by ISL is partly mediated by ROS. Together, these findings will provide theory and experimental basis for ISL clinical use in treatment of atherosclerosis.

\section{Results}

Effect of Isoliquiritigenin on human aortic smooth muscle cell viability

We first examined effect of different dose of ISL on HASMCs cell viability. Results showed that ISL inhibited cell viability of HASMCs in a dose dependent manner and the IC50 of ISL to HASMCs was $18.47 \mu \mathrm{M}$ (Fig. 1a). Subsequently, $10 \mu \mathrm{M}$ ISL was used to treat HASMCs at different time points and we observed that ISL also inhibited cell viability of HASMCs in a time dependent manner (Fig. 1b).

To identify whether decreased HASMCs viability induced by ISL was associated with increased cell death, we performed PI staining. Result showed that ratio of PI positive cells in ISL treated HASMCs was a little higher than that in ISL untreated cells. This result demonstrated that ISL didn't induce cell death.

\section{Effect of Isoliquiritigenin on cell cycle progression of HASMCs}

To explore effect of ISL on cell cycle progression, we first investigated DNA synthesis in ISL treated or untreated HASMCs by BrdU incorporation. Results showed that BrdU inhibited HASMCs DNA synthesis in a dose dependent manner. (Fig. 2a). Cell cycle analysis revealed that ISL significantly increased the ratio of G1/ $\mathrm{S}$ cells and reduced the cells in $\mathrm{S}$ phase (Fig. $2 \mathrm{~b}$ ). These results demonstrated that ISL could significantly block the progression of cell cycle.

To explore whether ISL induced cell cycle blockage attributed to changes of cell cycle regulatory molecules, we checked the expressions of p27, CyclinD1 and CyclinE in ISL treated or untreated HASMCs. Results showed that the expression of p27 was upregulated in ISL treated HASMCs compared to untreated cells. In contrast, the expressions of CyclinD1 and CyclinE were down-regulated in ISL treated cells (Fig. 2c). These results demonstrated that ISL induced cell cycle arrest via modulating cell cycle regulatory molecules.
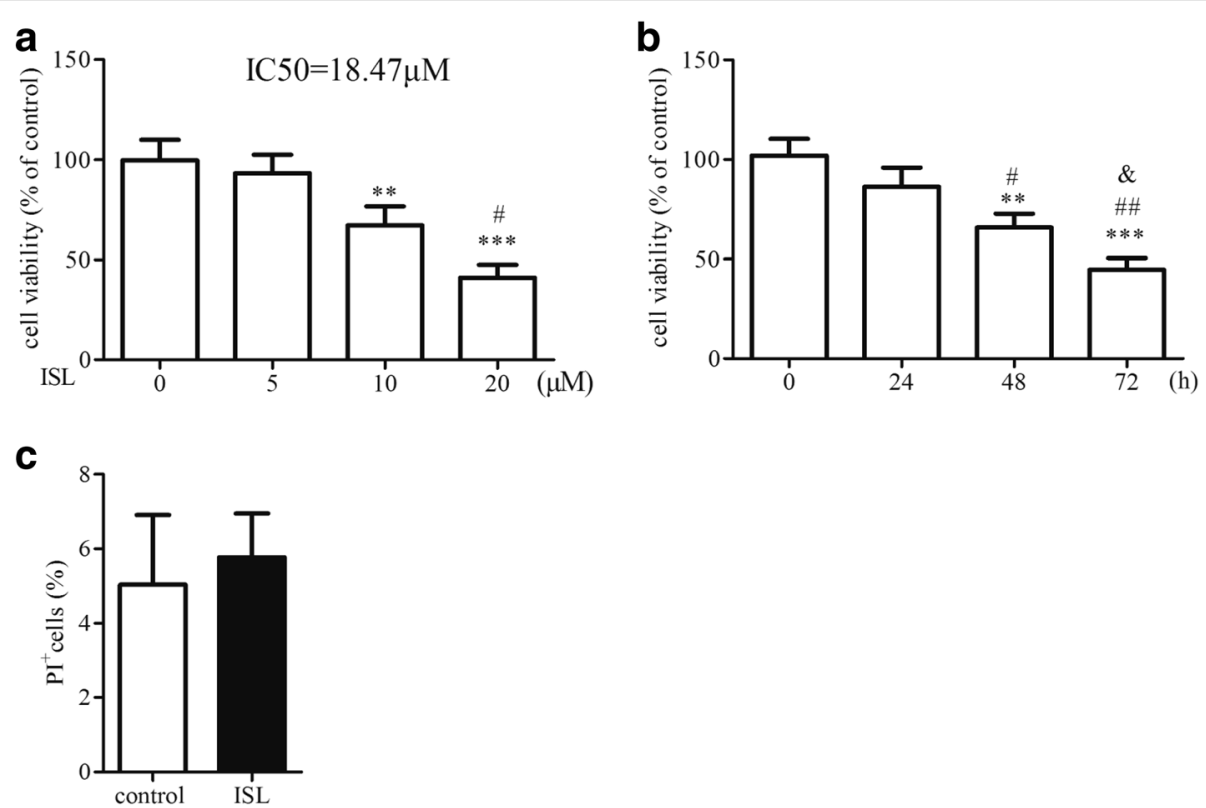

Fig. 1 Effect of Isoliquiritigenin on human aortic smooth muscle cell expansion. a After incubation with various concentrations of ISL for $48 \mathrm{~h}$, HASMCs cell viability was examined by CCK-8 assay. $\mathbf{b}$ HASMCs were treated with ISL (10 $\mu$ M) for different time points and the cell viability was detected by cck8 assay. c HASMCs were treated with ISL $(10 \mu \mathrm{M})$ for $48 \mathrm{~h}$ and cell death was determined by PI staining. All values represented as mean \pm SD, $n=5,{ }^{* *}: P<0.01$; ***: $P<0.001$ compared with untreated HASMCs. \#: $P<0.05$; \#\#: $P<0.01$, for (a) compared with $10 \mu \mathrm{M}$ ISL treated HASMCs; for (b) compared with ISL treated HASMCs for $24 \mathrm{~h}$. \&: $P<0.05$ compared with ISL treated HASMCs for $48 \mathrm{~h}$ 


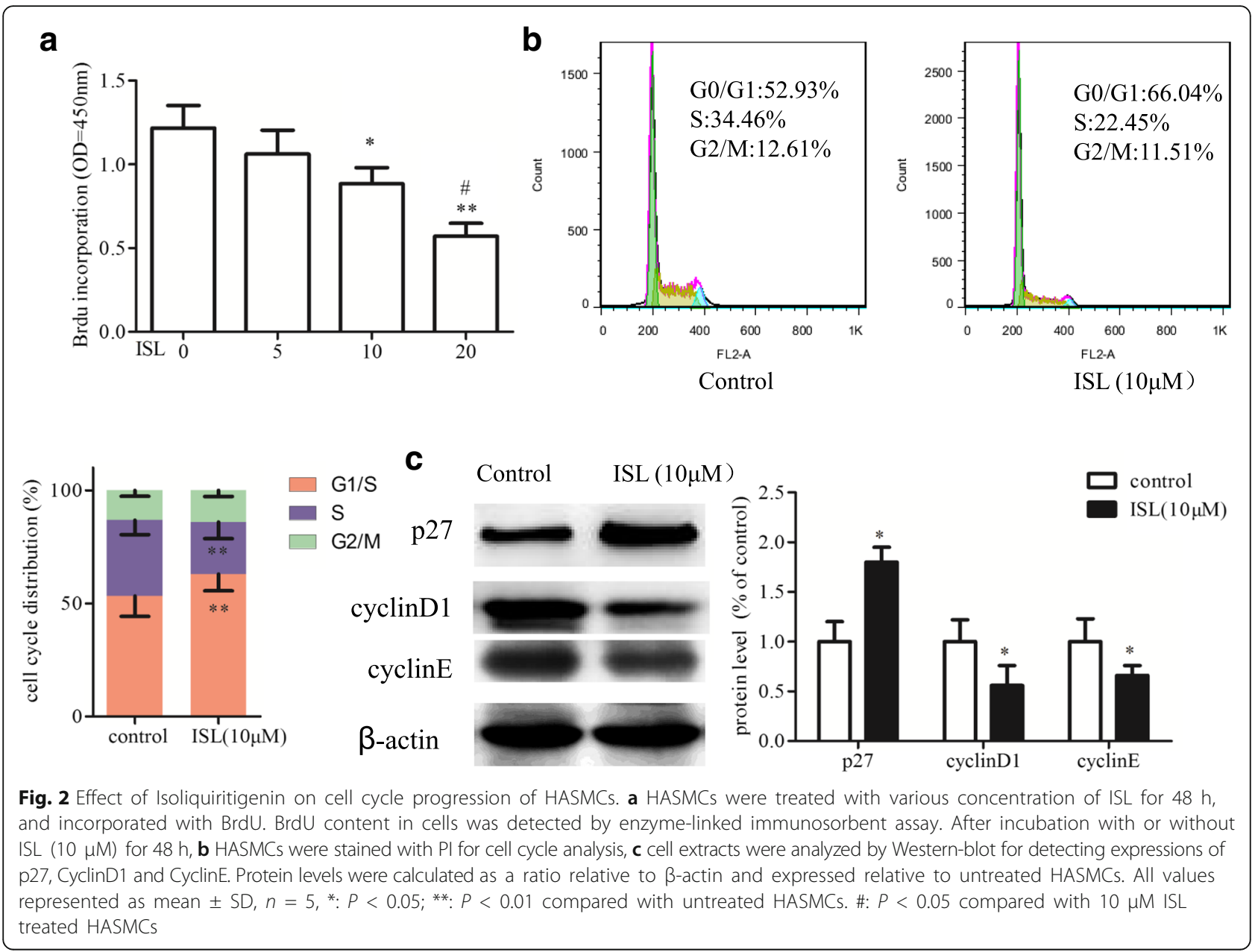

Effect of Isoliquiritigenin on ROS production in HASMCs Considered that ROS is required for VSMC proliferation and ISL has a property of antioxidant. We examined ROS level by flow cytometry in ISL treated or untreated HASMCs. Results showed that ROS level was reduced significantly by ISL treatment (Fig. 3a). Furthermore, SOD activity was obvious higher in ISL treated HASMCs than that of untreated cells (Fig. 3b).

\section{Effect of Isoliquiritigenin on signaling pathway related to $\mathrm{PI} 3 \mathrm{~K} / \mathrm{AKT}$}

ISL is reported as an inhibitor for PI3K-AKT signaling pathway [12]. Therefore, we wondered that if there are any molecular alternations of PI3K-AKT signaling pathway between control and ISL treated HASMCs. Western blot analysis revealed that although total expression of PI3K or AKT were not affected by ISL treatment, both the expressions of pPI3K and p-AKT were down-regulated in ISL treated HASMCs (Fig. 4).
$\mathrm{H}_{2} \mathrm{O}_{2}$ abolished the inhibitory effect of Isoliquiritigenin on HASMCs proliferation

To explore whether $\mathrm{H}_{2} \mathrm{O}_{2}$ could restore the proliferation of HASMCs, we treated cells with $\mathrm{H}_{2} \mathrm{O}_{2}$, ISL or ISL combined with $\mathrm{H}_{2} \mathrm{O}_{2}$. CCK8 assay revealed that $\mathrm{H}_{2} \mathrm{O}_{2}$ abolished the inhibitory effect of. ISL on HASMCs proliferation (Fig. 5a). Western blot analysis revealed that the decreased expressions of p-PI3K and p-AKT in ISL treated HASMCs were partly corrected by $\mathrm{H}_{2} \mathrm{O}_{2}$ administration (Fig. 5b).

\section{Discussion}

ISL, one of the major active components in licorice, possesses multiple biological activities including antioxidant, anti-inflammation and anti-tumor $[8,9,19]$. Several studies indicated the protective effects of ISL on cardiac and vessels, such as enhancing the cardiac and aortic muscle contractility, dampening cardiac injury caused by ischemia-reperfusion and down regulating cytokine induced cell adhesion molecules expression in endothelial cell [11, 19-21]. However, the effect of ISL on VSMCs proliferation remains to be investigated. In 


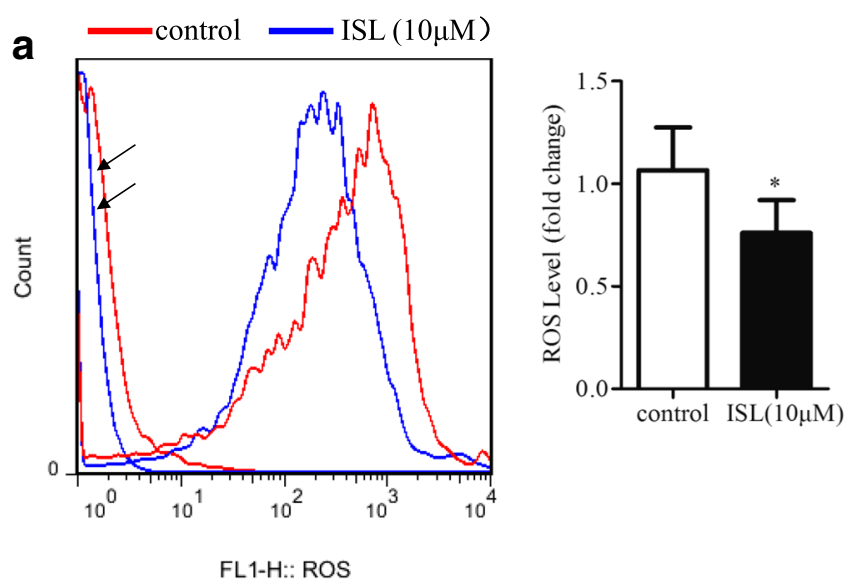

b

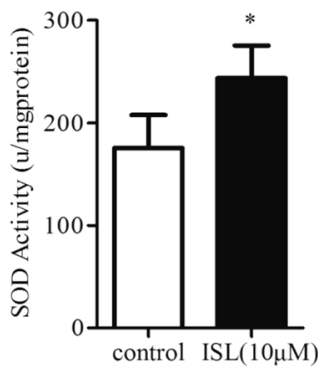

Fig. 3 Effect of Isoliquiritigenin on ROS production. a Flow cytometry analysis of reactive oxygen species in ISL (10 $\mu M$ ) treated or untreated HASMCs for $48 \mathrm{~h}$. DCFDA was used for intracellular ROS labeling. The ROS levels were calculated as a ratio of relative to untreated HASMCs. $\mathbf{b}$ Total SOD enzyme activity in cells were determined by SOD activity test. All values represented as mean \pm SD, $n=5, *$ : $P<0.05$ compared with untreated HASMCs. Arrows indicated autofluorescence

the present study, we found that ISL inhibited the HASMCs proliferation via blocking cell cycle progression. These results are similar to the inhibitory effect of ISL on proliferation of endothelia cells [22].

The cell cycle is tightly regulated by cell cycle regulatory molecules such as phosphorylated retinoblastoma protein (pRB), cyclins, cyclin dependent kinase (CDK) and CDK inhibitors (CDKI) [23]. The G1/S transition is mainly controlled by CyclinD-CDK4 and CyclinE-CDK2 complexes [24]. And, the interaction between CDK and cyclins could be inactivated by CDKI, such as p21 or p27 [25]. Here, we found that ISL could induce the cell cycle arrest of HASMCs in G1/S phase. Further exploration demonstrated that ISL down regulated the expressions of cyclinD1 and cyclinE in HASMCs whereas up regulated p27 expression.

It is well known that oxidative stress-induced proliferation of VSMCs plays a critical role in pathogenesis of atherosclerosis [26-28], and a mount of molecules were demonstrated to inhibit HASMCs proliferation mainly via attenuating oxidative stress [5, 7, 29-32]. Here, we found that ISL could effectively lowered ROS level in HASMCs and this may attribute to the increased SOD activity. Furthermore, $\mathrm{H}_{2} \mathrm{O}_{2}$ treatment recovered the proliferative ability of ISL-treated HASMCs. However, the exact mechanisms of ISL on oxidative stress regulation remain to be investigated.

PI3K/AKT signaling pathway is associated with cell proliferation and survive [33, 34]. Recent studies have identified that ISL is a kind of nature inhibitors of PI3K/ AKT signaling in breast cancer [12]. We found that ISL administration could down regulated the expression of molecules in PI3K/AKT signaling pathway, including pPI3K and $\mathrm{p}-\mathrm{AKT}$. Previous studies reveal that ROS could modulate the PI3K/AKT pathway through inactivating PTEN [17]. In consistent with this, we found that $\mathrm{H}_{2} \mathrm{O}_{2}$

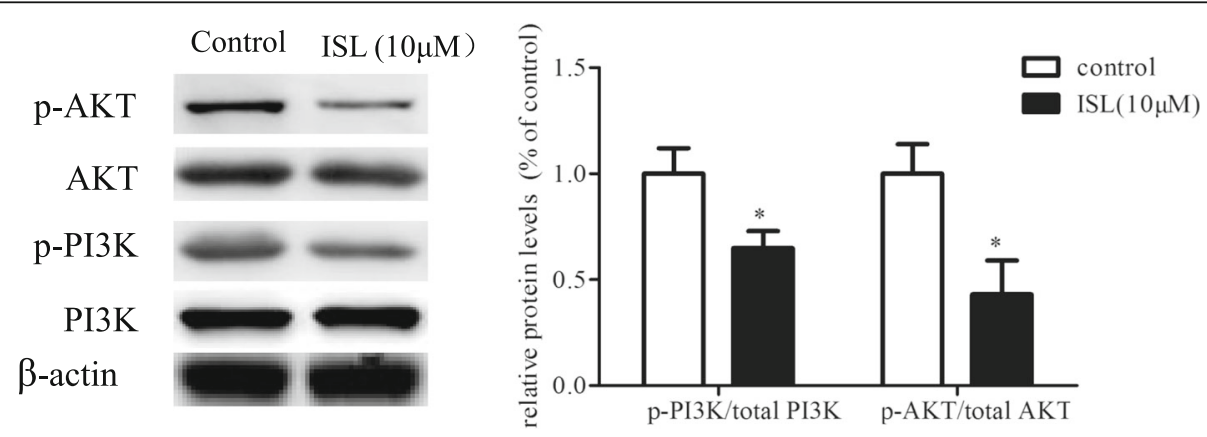

Fig. 4 Effect of Isoliquiritigenin on signaling pathway related to PI3K/AKT. Western blot analysis of cell extracts from ISL (10 $\mu M)$ treated or untreated HASMCs for $48 \mathrm{~h}$ for detecting expressions of PI3K, p-PI3K, AKT, p-AKT. Phosphorylated protein levels were calculated as a ratio relative to total protein and expressed relative to untreated HASMCs. All values represented as mean $\pm \mathrm{SD}, n=5, *: P<0.05$; **: $P<0.01$ compared with untreated HASMCS 

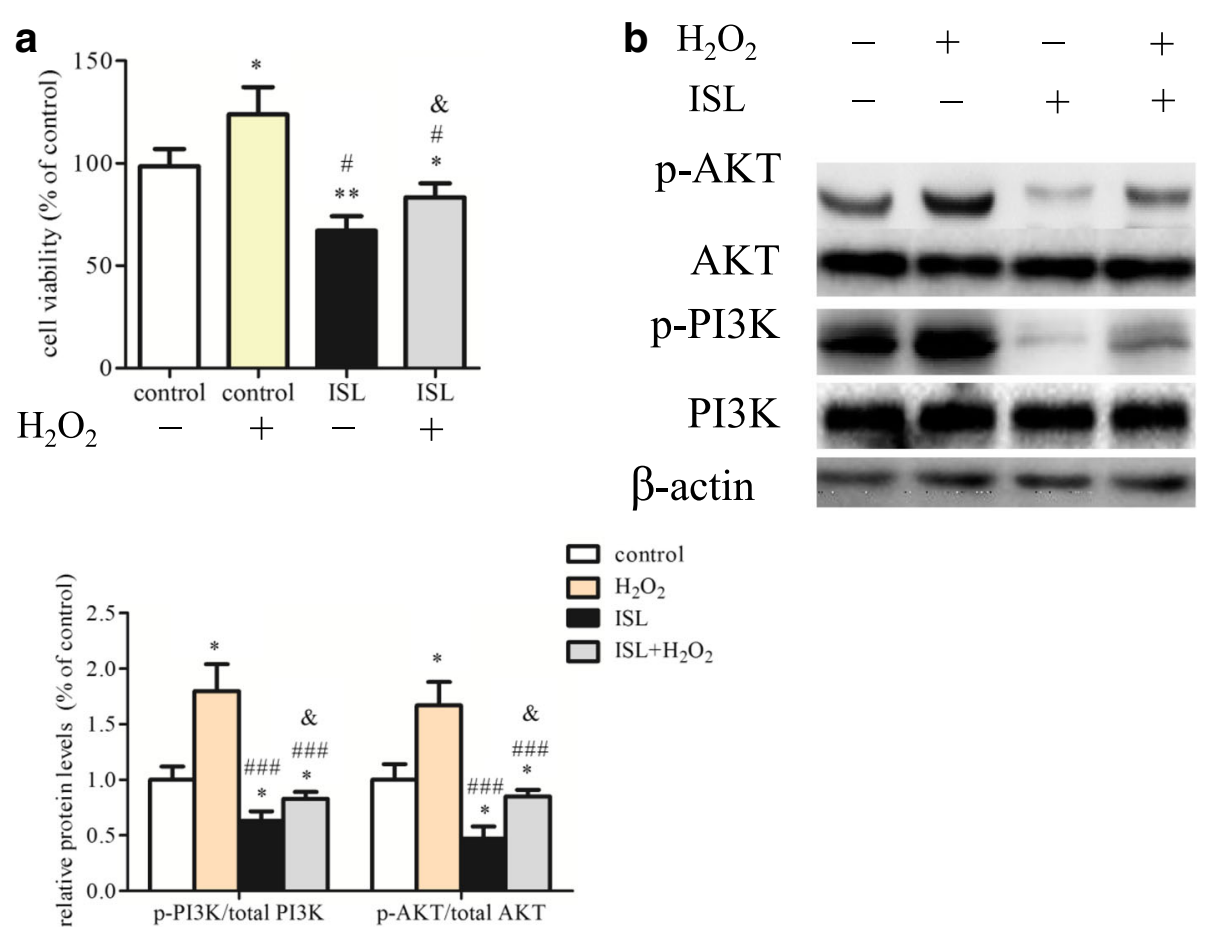

Fig. $5 \mathrm{H}_{2} \mathrm{O}_{2}$ abolished effect of Isoliquiritigenin on HASMCs proliferation. After incubation with or without ISL (10 $\mu \mathrm{M}$ ) in the absence or presence of $\mathrm{H}_{2} \mathrm{O}_{2}(100 \mu \mathrm{M})$ for $48 \mathrm{~h}$, a HASMCs viability was examined by cck-8 assay. $\mathbf{b}$ Western blot analysis of cell extracts for detection expressions of PI3K, p-PI3K, AKT, p-AKT. Phosphorylated protein levels were calculated as a ratio relative to total protein and expressed relative to untreated HASMCs. All values represented as mean $\pm \mathrm{SD}, n=5$, $^{*} P<0.05 ;{ }^{*}: P<0.01$ compared with untreated HASMCs. \#: $P<0.05$; \#\#\#: $P<0.05$ compared with $100 \mu \mathrm{M} \mathrm{H} \mathrm{O}_{2}$ treated HASMCs. \&: $P<0.05$ compared with ISL treated HASMCs

addition partly rescued the expressions of both p-PI3K and $\mathrm{p}$-AKT in ISL treated HASMCs.

It has been noted that ISL also exhibit significant estrogenic property. Estrogen receptors such as ER $\alpha$ and ER $\beta$ are expressed in VSMC [35]. Several studies have demonstrated that estrogen can inhibit the proliferation of VSMC via binding estrogen receptors, thereby protecting cardiovascular system from cardiovascular events [36, 37]. Estrogen signaling pathway can activate both PI3K/AKT pathway and antioxidant system in cells [38, 39]. However, whether the inhibitory effect of ISL on HASMCs proliferation depend on its estrogenic activity remains to be investigated.

In conclusion, we demonstrated that ISL could inhibit the proliferation of HASMCs through alleviating ROS and down-regulating molecules in PI3K/AKT signaling pathway. Furthermore, the inhibitory effect of ISL on PI3K/AKT signaling pathway, at least partly, depended on its function on ROS scavenging.

\section{Conclusion}

This is the first paper toward investigating the role of ISL in HASMCs proliferation. Our results showed that ISL specifically inhibited the proliferation of HASMCs in a dose and time dependent manner. Further study demonstrated that ISL arrested cells cycle in G1/S phase via up-regulating p27 and down-regulating CyclinD1 and CyclinE. These results are consistent with the previous report which investigates the effect of ISL on proliferation of endothelia. It is generally accepted that both ROS and PI3K/AKT signaling contribute to the proliferation of HASMCs. Numerous studies have demonstrated ISL could inhibit ROS generation and serve as an inhibitor of PI3K/AKT signaling. Therefore, we investigated whether treatment with ISL would have influences on ROS production and PI3K/ AKT signaling in HASMCs. We found that ISL could significantly inhibit ROS production and the expressions of molecules in PI3K/AKT signaling. And $\mathrm{H} 2 \mathrm{O} 2$ administration partially abolished the inhibitory effect of ISL on HASMCs proliferation. We also found that $\mathrm{H} 2 \mathrm{O} 2$ could reactivate PI3K/AKT signaling in ISL treated HASMCs.

These results suggest that the ROS-scavenging property of ISL plays a crucial role in inhibiting the proliferation of HASMCs. Our data also reveal that PI3K/AKT signaling is an effector of ROS in regulating HASMCs proliferation. Overall, this study provides additional evidence to support the view that ISL play roles in protecting cardiovascular disorders. 


\section{Methods}

\section{Cell culture and treatment}

Primary HASMCs was purchased from YRgene (NC008, China) and preserved in our lab. The cells were maintained in Dulbecco's modified Eagle's medium (DMEM, Gibco, USA) supplemented with $10 \%$ fetal bovine serum (Gibco, USA) at $37{ }^{\circ} \mathrm{C}$ in an atmosphere of $5 \% \mathrm{CO}_{2}$ and 95\% air. ISL with a purity of $98 \%$ was purchased from Sigma Aldrich (Japan) and dissolved in DSMO. HASMCs were treated with ISL alone, $\mathrm{H}_{2} \mathrm{O}_{2}$ alone or ISL combined with $\mathrm{H}_{2} \mathrm{O}_{2}$ at designed concentrations and time points. Cells cultured in the medium containing DMSO were used as a control.

\section{Cell Counting Kit-8 assay}

Cell viability was detected by a Cell Counting Kit-8 (CCK-8, beyotime biotechnology of Nanjing, China). Cultured HASMCs were passaged onto 96-well culture plates (Corning, USA) at a density of $1 \times 10^{4}$ cells/well. After being treated with ISL, $\mathrm{H}_{2} \mathrm{O}_{2}$ or ISL combined with $\mathrm{H}_{2} \mathrm{O}_{2}, \mathrm{CCK}-8$ assay was performed in accordance with the manufacturer's instructions. The absorbance was determined at $450 \mathrm{~nm}$ by microplate reader (Thermo fisher scientific, USA). Cell viability was calculated relative to untreated HASMCs.

\section{Brdu incorporation}

HASMCs were planted onto 96-well plates (Corning, USA) at a density of $1 \times 10^{4} /$ well and incubated with various dose of ISL for $48 \mathrm{~h}$. BrdU cell proliferation ELISA kit (Abcam, USA) was used. Briefly, cells were treated with BrdU solution for $12 \mathrm{~h}$. Afer cell fixation, anti BrdU antibody was added in the plates for $1 \mathrm{~h}$ in room temperature. Then, cells were washed three times in PBS and incubated with secondary antibody for $30 \mathrm{~min}$ at room temperature. Finally, after incubation with TMB and stop solution, the absorbance was determined at $450 \mathrm{~nm}$ by microplate reader (Thermo fisher scientific, USA).

\section{Flow cytometry analysis of cell cycle distribution}

The cultured HASMCs were seeded on six-well plates at a density of $2 \times 10^{5} /$ well. The cells were treated with $10 \mu \mathrm{M}$ ISL for $48 \mathrm{~h}$ and untreated cells were set up as control. For cell cycle analysis, cells were collected and re-suspended in $70 \%$ ethanol and stored at $4{ }^{\circ} \mathrm{C}$ overnight for fixation. The cells were washed in PBS for twice and incubated with propidium iodide $(50 \mathrm{mg} / \mathrm{ml})$ (PI; invitrogen, USA) at $4{ }^{\circ} \mathrm{C}$ for 30 mins. The samples were analyzed by flow cytometry (Becton Dickinson, USA); For cell death assay, cells were collected and resuspended in PBS and incubated with propidium iodide $(50 \mathrm{mg} / \mathrm{ml})(\mathrm{PI}$; invitrogen, USA) at room temperature for 30 mins. The samples were analyzed by flow cytometry (Becton Dickinson, USA).

\section{Western blot}

HASMCs were collected and lysed in RIPA buffer (pH 7.4) containing 2-amino-2-hydroxymethyl-propane1,3-diol (Tris)- $\mathrm{HCl}$ (50 mM), $\mathrm{NaCl}$ (150 mM), EDTA (1 $\mathrm{mM})$, Triton-X (1\%), sodium deoxycholate $(0.5 \%)$ and SDS (0.1\%).

The homogenates were centrifuged at $13000 \mathrm{r} / \mathrm{min}$ for $15 \mathrm{~min}$ at $4{ }^{\circ} \mathrm{C}$ and the supernatant was obtained. Proteins were fractured by electrophoresis on a $10 \%$ SDSpolyacrylamide gel and transferred on onto PVDF membrane (Millipore, USA). Membranes were soaked in 5\% milk/PBST for blocking.

Then, membranes were incubated with antibodies to p27kip1 (Abcam, USA), CyclinE (CST, USA), CyclinD1 (CST, USA), PI3K (Abcam, USA), p-PI3K (Abcam, USA), AKT (Abcam, USA), p-AKT (Abcam, USA) overnight at $4{ }^{\circ} \mathrm{C}$. The membrane washed three times in PBST and Hrp-conjucated secondary antibody goat antirabbit or goat anti-mouse (Abcam, USA) were added on the membranes for $1 \mathrm{~h}$ in room temperature. Protein bands were visualized by staining with enhanced chemiluminescence (ECL).

\section{Flow cytometry analysis of ROS}

HASMCs were digested by trpsin and re-suspended in $1 \mathrm{ml}$ 2\% BSA (beyotime biotechnology of Nanjing; China)/PBST. The cells were stained with DCFDA $\left(2^{\prime}, 7^{\prime}\right.$-Dichlorofluorescin diacetate, Sigma Aldrich, Japan) in dark at $37{ }^{\circ} \mathrm{C}$ for $30 \mathrm{~min}$. Then the cells were washed three times in PBS and subjected to flow cytometry analysis (Becton Dickinson, USA).

\section{Biochemical test of SOD activity}

HASMCs were collected and homogenized in $10 \%$ salt solution. The homogenate was centrifuged at $13000 \mathrm{r} /$ $\min$ at $4{ }^{\circ} \mathrm{C}$ for $10 \mathrm{~min}$ and the supernatant was collected for biochemical detection. Commercial kit (Nanjing Jiancheng Bioengineering Institute, China) was purchased for SOD activity determination. The procedures were conducted in accordance with the instructions of manufacturer.

\section{Data analysis}

Datas are expressed as mean \pm SD. Unpaired Sudent's test was used for comparison between two groups. For more than two groups one-way ANOVA was used and after ANOVA, Bonferroni test was used. $P<0.05$ is indicated as statistically significant. 


\section{Abbreviations}

HASMCs: Human arterial smooth muscle cells; ISL: Isoliquiritigenin; ROS: Reactive oxygen species; SOD: Superoxide dismutase; VSMCs: Vascular smooth muscle cells

\section{Acknowledgments}

Not applicable.

\section{Funding}

This project was supported by personal donation from Dr. Ronglin (The corresponding author).

\section{Availability of data and materials}

The datasets used and/or analyzed during the current study are available from the corresponding author on reasonable request.

\section{Authors' contributions}

TBC and RL designed the study. TBC and SXD performed experiments. TBC and RL analyzed results. TBC, RL and SXD wrote the manuscript; All authors contributed substantially to the work presented in this paper, and critically reviewed the results, read and approved the final manuscript for submission.

\section{Ethics approval and consent to participate}

Not applicable.

\section{Consent for publication}

Not applicable.

\section{Competing interests}

The authors declare that they have no competing interests.

\section{Publisher's Note}

Springer Nature remains neutral with regard to jurisdictional claims in published maps and institutional affiliations.

\section{Author details}

'Department of Cardiology, First Hospital of Quanzhou Affiliated to Fujian Medical University, NO. 205, East Street, Licheng District, Quanzhou, Fujian, China. ${ }^{2}$ Quanzhou Medical College, NO. 2, Anji Street, Luojiang District, Quanzhou, Fujian, China.

Received: 12 December 2016 Accepted: 9 July 2017

Published online: 17 July 2017

\section{References}

1. Bennett MR, Sinha S, Owens GK. Vascular Smooth Muscle Cells in Atherosclerosis. Circ Res. 2016:118(4):692-702. doi:10.1161/CIRCRESAHA.115. 306361. PubMed PMID: 26892967; PubMed Central PMCID: PMC4762053

2. Lee $\mathrm{KY}$, Lee $\mathrm{DH}$, Choi HC. Mesoglycan attenuates VSMC proliferation through activation of AMP-activated protein kinase and mTOR. Clin Hypertens. 2015;22:2. doi:10.1186/s40885-016-0037-x. PubMed PMID: 26893937; PubMed Central PMCID: PMC4750809

3. Zhao J, Jian L, Zhang L, Ding T, Li X, Cheng D, Niu S, Sun L, Li E, Liu S, Jiang $Y$, Liu L. Knockdown of SCARA5 inhibits PDGF-BB-induced vascular smooth muscle cell proliferation and migration through suppression of the PDGF signaling pathway. Mol Med Rep. 2016;13(5):4455-60. doi:10.3892/mmr.2016. 5074. PubMed PMID: 27035566

4. Won KJ, Jung SH, Lee CK, Na HR, Lee KP, Lee DY, Park ES, Choi WS, Shim SB, Kim B. DJ-1/park7 protects against neointimal formation via the inhibition of vascular smooth muscle cell growth. Cardiovasc Res. 2013;97(3):553-61. doi:10.1093/cvr/cvs363. PubMed PMID: 23230227

5. Zhou Y, Zhang MJ, Li BH, Chen L, Pi Y, Yin YW, Long CY, Wang X, Sun MJ, Chen X, Gao CY, Li JC, Zhang LL. PPARgamma Inhibits VSMC Proliferation and Migration via Attenuating Oxidative Stress through Upregulating UCP2. PLoS One. 2016:11(5):e0154720. doi:10.1371/journal.pone.0154720. PubMed PMID: 27144886; PubMed Central PMCID: PMC4856345

6. Bourmoum M, Charles R, Claing A. The GTPase ARF6 Controls ROS Production to Mediate Angiotensin II-Induced Vascular Smooth Muscle Cell Proliferation. PLoS One. 2016:11(1):e0148097. doi:10.1371/journal.pone. 0148097. PubMed PMID: 26824355; PubMed Central PMCID: PMC4732744
7. Guo R, Li W, Liu B, Li S, Zhang B, Xu Y. Resveratrol protects vascular smooth muscle cells against high glucose-induced oxidative stress and cell proliferation in vitro. Med Sci Monit Basic Res. 2014;20:82-92. doi:10.12659/ MSMBR.890858. PubMed PMID: 24971582; PubMed Central PMCID: PMC4095779

8. Zhang X, Yeung ED, Wang J, Panzhinskiy EE, Tong C, Li W, Li J. Isoliquiritigenin, a natural anti-oxidant, selectively inhibits the proliferation of prostate cancer cells. Clin Exp Pharmacol Physiol. 2010;37(8):841-7. doi:10. 1111/j.1440-1681.2010.05395.x. PubMed PMID: 20456427

9. Traboulsi H, Cloutier A, Boyapelly K, Bonin MA, Marsault E, Cantin AM, Richter MV. The Flavonoid Isoliquiritigenin Reduces Lung Inflammation and Mouse Morbidity during Influenza Virus Infection. Antimicrob Agents Chemother. 2015:59(10):6317-27. doi:10.1128/AAC.01098-15. PubMed PMID: 26248373; PubMed Central PMCID: PMC4576023

10. Kwon HM, Choi YJ, Choi JS, Kang SW, Bae JY, Kang IJ, Jun JG, Lee SS, Lim SS, Kang YH. Blockade of cytokine-induced endothelial cell adhesion molecule expression by licorice isoliquiritigenin through NF-kappaB signal disruption. Exp Biol Med. 2007;232(2):235-45. PubMed PMID: 17259331

11. Kumar S, Sharma A, Madan B, Singhal V, Ghosh B. Isoliquiritigenin inhibits IkappaB kinase activity and ROS generation to block TNF-alpha induced expression of cell adhesion molecules on human endothelial cells. Biochem Pharmacol. 2007;73(10):1602-12. doi:10.1016/j.bcp.2007.01.015. PubMed PMID: 17276410

12. Safdari $Y$, Khalili M, Ebrahimzadeh MA, Yazdani $Y$, Farajnia S. Natural inhibitors of PI3K/AKT signaling in breast cancer: emphasis on newlydiscovered molecular mechanisms of action. Pharmacol Res. 2015;93:1-10. doi:10.1016/j.phrs.2014.12.004. PubMed PMID: 25533812

13. Li Q, Li G, Lan X, Zheng M, Chen KH, Cao CM, Xiao RP. Receptor interacting protein 3 suppresses vascular smooth muscle cell growth by inhibition of the phosphoinositide 3-kinase-Akt axis. J Biol Chem. 2010;285(13):9535-44. doi:10.1074/jbc.M109.071332. PubMed PMID: 20042608; PubMed Central PMCID: PMC2843204

14. Cui L, Bai Y, Zhang J, Zhang S, Xu J. Effects of extracellular acid stimulation on rat vascular smooth muscle cell in Gas6/Axl or PI3K/Akt signaling pathway. Clin Exp Hypertens. 2016;38(5):451-6. doi:10.3109/10641963.2016. 1163366. PubMed PMID: 27362907

15. Wang L, Zhu LH, Jiang H, Tang QZ, Yan L, Wang D, Liu C, Bian ZY, Li H. Grape seed proanthocyanidins attenuate vascular smooth muscle cell proliferation via blocking phosphatidylinositol 3-kinase-dependent signaling pathways. J Cell Physiol. 2010;223(3):713-26. doi:10.1002/jcp.22080. PubMed PMID: 20175116

16. Leslie NR, Downes CP. PTEN: The down side of PI 3-kinase signalling. Cell Signal. 2002;14(4):285-95. PubMed PMID: 11858936

17. Lee SR, Yang KS, Kwon J, Lee C, Jeong W, Rhee SG. Reversible inactivation of the tumor suppressor PTEN by H2O2. J Biol Chem. 2002;277(23):2033642. doi:10.1074/jbc.M111899200. PubMed PMID: 11916965

18. Murata $H$, Ihara $Y$, Nakamura $H$, Yodoi J, Sumikawa K, Kondo T. Glutaredoxin exerts an antiapoptotic effect by regulating the redox state of Akt. J Biol Chem. 2003:278(50):50226-33. doi:10.1074/jbc.M310171200. PubMed PMID: 14522978

19. Zhan C, Yang J. Protective effects of isoliquiritigenin in transient middle cerebral artery occlusion-induced focal cerebral ischemia in rats. Pharmacol Res. 2006:53(3):303-9. doi:10.1016/j.phrs.2005.12.008. PubMed PMID: 16459097

20. Wegener JW, Nawrath $\mathrm{H}$. Differential effects of isoliquiritigenin and YC-1 in rat aortic smooth muscle. Eur J Pharmacol. 1997:323(1):89-91. PubMed PMID: 9105881

21. Wegener JW, Nawrath $\mathrm{H}$. Cardiac effects of isoliquiritigenin. Eur J Pharmacol. 1997;326(1):37-44. PubMed PMID: 9178653

22. Wang Z, Wang N, Han S, Wang D, Mo S, Yu L, Huang H, Tsui K, Shen J, Chen J. Dietary compound isoliquiritigenin inhibits breast cancer neoangiogenesis via VEGFNEGFR-2 signaling pathway. PLoS One. 2013:8(7): e68566. doi:10.1371/journal.pone.0068566. PubMed PMID: 23861918 PubMed Central PMCID: PMC3702614

23. Hayashi Y. Mechanism of tumorigenesis caused by tumor suppressor gene. Nihon Rinsho. 2000;58(6):1231-6. PubMed PMID: 10879046

24. Lee MH, Yang HY. Regulators of G1 cyclin-dependent kinases and cancers. Cancer Metastasis Rev. 2003;22(4):435-49. PubMed PMID: 12884917

25. Musat M, Vax W, Borboli N, Gueorguiev M, Bonner S, Korbonits M, Grossman AB. Cell cycle dysregulation in pituitary oncogenesis. Front Horm Res. 2004;32:34-62. PubMed PMID: 15281339 
26. Hadrava V, Kruppa U, Russo RC, Lacourciere Y, Tremblay J, Hamet P. Vascular smooth muscle cell proliferation and its therapeutic modulation in hypertension. Am Heart J. 1991;122(4 Pt 2):1198-203. PubMed PMID: 1927887

27. Porreca E, Ucchino S, Di Febbo C, Di Bartolomeo N, Angelucci D, Napolitano AM, Mezzetti A, Cuccurullo F. Antiproliferative effect of desferrioxamine on vascular smooth muscle cells in vitro and in vivo. Arterioscler Thromb. 1994; 14(2):299-304. PubMed PMID: 8305423

28. Wang Y, Ji L, Jiang R, Zheng L, Liu D. Oxidized high-density lipoprotein induces the proliferation and migration of vascular smooth muscle cells by promoting the production of ROS. J Atheroscler Thromb. 2014;21(3):204-16. PubMed PMID: 24225481

29. Oyagbemi AA, Omobowale TO, Adedapo AA, Yakubu MA. Kolaviron, Biflavonoid Complex from the Seed of Garcinia kola Attenuated Angiotensin II- and Lypopolysaccharide-induced Vascular Smooth Muscle Cell Proliferation and Nitric Oxide Production. Pharm Res. 2016;8(Suppl 1):S50-5. doi:10.4103/0974-8490.178647. PubMed PMID: 27114693; PubMed Central PMCID: PMC4821108

30. Zhao Q, Zhang J, Wang H. PGC-1alpha limits angiotensin II-induced rat vascular smooth muscle cells proliferation via attenuating NOX1-mediated generation of reactive oxygen species. Biosci Rep. 2015;35(5) doi:10.1042/ BSR20150112. PubMed PMID: 26310573; PubMed Central PMCID: PMC4613698

31. Wu L, Zou H, Xia W, Dong Q, Wang L. Role of magnolol in the proliferation of vascular smooth muscle cells. Herz. 2015;40(3):542-8. doi:10.1007/s00059014-4051-z. PubMed PMID: 24595318

32. Yuan $X$, Zhang Z, Gong K, Zhao P, Qin J, Liu N. Inhibition of reactive oxygen species/extracellular signal-regulated kinases pathway by pioglitazone attenuates advanced glycation end products-induced proliferation of vascular smooth muscle cells in rats. Biol Pharm Bull. 2011;34(5):618-23. PubMed PMID: 21532147

33. Perugini RA, McDade TP, Vittimberga FJ Jr, Callery MP. Pancreatic cancer cell proliferation is phosphatidylinositol 3-kinase dependent. J Surg Res. 2000; 90(1):39-44. doi:10.1006/jsre.2000.5833. PubMed PMID: 10781373

34. Franke TF, Kaplan DR, Cantley LC. PI3K: downstream AKTion blocks apoptosis. Cell. 1997;88(4):435-7. PubMed PMID: 9038334

35. Somjen D, Kohen F, Gayer B, Knoll E, Limor R, Baz M, Sharon O, Posner GH, Stern N. A non-calcemic Vitamin D analog modulates both nuclear and putative membranal estrogen receptors in cultured human vascular smooth muscle cells. J Steroid Biochem Mol Biol. 2004;89-90(1-5):397-9. doi:10.1016/ j.jsbmb.2004.03.006. PubMed PMID: 15225808

36. Smirnova NF, Fontaine C, Buscato M, Lupieri A, Vinel A, Valera MC Guillaume M, Malet N, Foidart JM, Raymond-Letron I, Lenfant F, Gourdy P, Katzenellenbogen BS, Katzenellenbogen JA, Laffargue M, Arnal JF. The Activation Function-1 of Estrogen Receptor Alpha Prevents Arterial Neointima Development Through a Direct Effect on Smooth Muscle Cells. Circ Res. 2015;117(9):770-8. doi:10.1161/CIRCRESAHA.115.306416. PubMed PMID: 26316608; PubMed Central PMCID: PMC4596486

37. Nakamura Y, Suzuki T, Sasano H. Estrogen actions and in situ synthesis in human vascular smooth muscle cells and their correlation with atherosclerosis. J Steroid Biochem Mol Biol. 2005;93(2-5):263-8. doi:10.1016/ j.jsbmb.2004.12.024. PubMed PMID: 15860269

38. Strehlow K, Rotter S, Wassmann S, Adam O, Grohe C, Laufs K, Bohm M, Nickenig G. Modulation of antioxidant enzyme expression and function by estrogen. Circ Res. 2003;93(2):170-7. doi:10.1161/01.RES.0000082334.17947. 11. PubMed PMID: 12816884

39. Borahay MA, Asoglu MR, Mas A, Adam S, Kilic GS, Al-Hendy A. Estrogen Receptors and Signaling in Fibroids: Role in Pathobiology and Therapeutic Implications. Reprod Sci. 2016; doi:10.1177/1933719116678686. PubMed PMID: 27872195

\section{Submit your next manuscript to BioMed Central and we will help you at every step:}

- We accept pre-submission inquiries

- Our selector tool helps you to find the most relevant journal

- We provide round the clock customer support

- Convenient online submission

- Thorough peer review

- Inclusion in PubMed and all major indexing services

- Maximum visibility for your research

Submit your manuscript at www.biomedcentral.com/submit 